\title{
Ultrasound Changes of Peri-Ankle Muscles in Subjects with Unilateral Chronic Ankle Instability
}

\author{
Khadijeh Kazemi ${ }^{1}$, Feryal Saadi² ${ }^{2}$ Khodabakhsh Javanshir ${ }^{3}$, Mohammad Jafar Shaterzadeh Yazdi ${ }^{4}$, \\ Shahin Goharpey ${ }^{5}$, Seyyed Shirmard Miraali ${ }^{6}$, Gholamhossein Nassadj ${ }^{7}$
}

\begin{abstract}
${ }_{1}^{1}$ Department of Physiotherapy, Musculoskeletal Rehabilitation Research Center, Ahvaz Jundishapur University of Medical Sciences, Ahvaz, Iran. ${ }^{2}$ Department of Radiology, Ahvaz Jundishapur University of Medical Sciences, Ahvaz, Iran. ${ }^{3}$ Department of Physiotherapy, Mobility Impairment Research Center, Babol University of Medical Sciences, Babol, Iran. 4, 5 Department of Physiotherapy, Musculoskeletal Rehabilitation Research Center, Ahvaz

Jundishapur University of Medical Sciences, Ahvaz, Iran. ${ }^{6}$ Department of Radiology, Ahvaz Jundishapur University of Medical Sciences, Ahvaz, Iran. ${ }^{7}$ Department of Physiotherapy, Musculoskeletal Rehabilitation Research Center, Ahvaz Jundishapur University of Medical Sciences, Ahvaz, Iran.
\end{abstract}

\section{ABSTRACT}

\section{BACKGROUND}

Ankle sprain is a common problem among active people and athletes. About $80 \%$ of the people and $73 \%$ of the athletes, who once had an ankle sprain, have experienced a recurrence of ankle sprain during their work or sport. Chronic ankle instability is described as a repeated ankle sprain, ankle giving way, pain and swelling and functional decline. Due to impaired muscle strength and impaired neuromuscular and postural control, it seems that the morphological criteria of peri-ankle muscles have changed. The study aimed to identify the morphological and muscle performance components of peroneus longus (PL) muscle in subjects with injured and intact sides of the chronic ankle sprain. Furthermore, the difference in ultrasonographic characteristics of PL muscle between genders, and the effect of the dominant limb on PL muscle ultrasonographic characteristics were investigated.

\section{METHODS}

The thickness, width and cross-sectional area (CSA) as morphological components and muscle performance components like fiber length, and pennation angle of PL muscle of the injured were calculated and compared to the intact side of the control in 25 subjects with unilateral chronic ankle instability via ultrasonography.

\section{RESULTS}

The findings of this study indicated a significant difference in the morphological component of PL muscle between both sides with no statistically significant difference in the muscle performance component of PL muscle.

\section{CONCLUSIONS}

Awareness of these changes in the injured side muscle morphology may lead to better clinical decision-making to design the best treatment plan by the physiotherapist.

\section{KEY WORDS}

Ankle Sprain, Chronic Ankle Instability, Ankle Muscle Ultrasonography
Corresponding Author: Gholamhossein Nassadj, Musculoskeletal Rehabilitation Research Center, Ahvaz Jundishapur University of Medical Sciences, PO Box - 33133 - 61357, Ahvaz, Iran. E-mail: nassadj-gh@ajums.ac.ir

DOI: $10.14260 /$ jemds/2021/145

How to Cite This Article:

Kazemi K, Saadi F, Javanshir K, et al. Ultrasound changes of peri ankle muscles in subjects with unilateral chronic ankle instability. J Evolution Med Dent Sci 2021;10(10):673-678, DOI: 10.14260/jemds/2021/145

Submission 10-10-2020, Peer Review 04-12-2020, Acceptance 10-12-2020, Published 08-03-2021.

Copyright (C) 2021 Khadijeh Kazemi et al. This is an open access article distributed under Creative Commons Attribution License [Attribution 4.0 International (CC BY 4.0)] 


\section{BACKGROUND}

Ankle sprain is a common problem among active people and athletes. ${ }^{1,2}$ The incidence of this injury is greater in young athletes, military personnel, and those who run and jump continuously. ${ }^{3-5}$ Ankle sprain is a major component of orthopaedic lesions and includes $7-10 \%$ of the patients admitted to emergency departments. ${ }^{6}$ The treatment and prevention of ankle sprain take a great amount of time in the medical field with an annual cost of $\$ 4$ billion in United States of America (USA). ${ }^{7}$ Most of ankle injuries are of inversion injury damaging the lateral ankle ligaments. ${ }^{8-11}$ The inversion ankle sprain is a multi-factorial injury. Accordingly, sudden ankle inversion is controlled by active and passive agents, which include muscle and soft tissue resistance. ${ }^{12}$ Moreover, ankle sprain can lead to prolonged absence of athlete from exercises, reduced activity of individuals and decreased quality of life. ${ }^{13-15}$ Mansfield and Neumann proposed that, the weakness of the peroneal muscles predisposes the foot to the inversion position, which is essential for inversion ankle sprains. ${ }^{16}$ About $80 \%$ of the people and $73 \%$ of the athletes, who once had an ankle sprain, have experienced recurrent ankle sprain during their work or sports. ${ }^{17-20}$

Chronic ankle instability (CAI) is described as a repeated ankle sprain, ankle giving way, pain and swelling, and functional decline. ${ }^{21,22}$ It also causes functional and mechanical defects leading to long-term proprioception impairment affecting the ankle and hip strategy in maintaining dynamic postural control. ${ }^{11}$ It has been confirmed that the postural control is impaired in people with CAI. ${ }^{23}$ Several electromyographic studies indicated the changes in the activity of evertor muscles during continuous walking and the changes in the activity of dorsiflexor, plantar flexor and evertor muscles during jumping in patients with CAI. ${ }^{24}$ Since foot evertor muscles resist inversion, they are the centre of attention in terms of ankle instability. ${ }^{6,25}$ It seems that, the weak evertor muscles cannot provide a protective contraction to prevent injury during an unexpected inversion of the ankle.6,26 Perceptual impairment, impaired muscular control, impaired strength and postural control impairment are considered as functional disabilities, but the changes in ankle function are related to the changes in morphology and physiology. ${ }^{27}$ Therefore, awareness of the structural changes and possible injuries to ankle structures might help to identify the risk of lateral ankle sprain and make decisions for rehabilitation following the injury. The primary objective of this study was to identify the morphological and muscle performance components of PL muscle in subjects with injured and intact sides of the chronic ankle instability. Secondary objectives were: 1) to determine difference in ultrasonographic characteristics of PL muscle between injured and intact sides and genders with unilateral CAI, and 2) to show if the dominant limb has an effect on PL muscle ultrasonographic characteristics.

\section{METHODS}

\section{Participants}

Twenty-five subjects (14 males and 11 females, $28.32 \pm 6.01$ years) with unilateral CAI participated in this case-control study. Fifty feet of 25 participants were involved ( 25 case, 25 control); the injured side of any participant was considered as the case group and his / her intact side was considered the control group, between November 2018 to October 2019.

Written informed consent was obtained from all the participants, and the protocol of the study was approved by Ethics committee of Ahvaz Jundishapur University of Medical Sciences (Ethical code: IR. AJUMS.REC.1397.530). The personal information was also obtained using the Cumberland Ankle Instability Tool (CAIT). The CAIT comprises of 9 items; each item scores individually and focuses on the symptoms of instability during several different physical tasks. In addition, 8 of the 9 questions were designed to explore the ankle instability during daily and sports activities and one question was focused on participants' pain. The total score of CAIT ranges from 0 - 30: lower scores indicate decreased ankle stability, and higher scores indicate increased stability. The left and right limbs are scored separately. ${ }^{16,28}$ The inclusion criteria were as follows: (a) age range of 18 - 40 years, ${ }^{16}$ (b) experiencing at least one inversion ankle sprain within 1 - 6 months with pain or swelling and temporary loss of ankle function, ${ }^{13,29}$ (c) experiencing at least two giving way during the last 6 months, ${ }^{29}$ (d) the Cumberland questionnaire score lower than 2730-32 and (e) subjective sense of instability in the ankle. ${ }^{29,32}$ Participants with large structural changes in lower extremities, neurological disorders, vestibular disorder, head trauma during the last 3 months, pregnancy, fractures in the lower extremities, musculoskeletal injuries of lower limb joints in the last 3 months, and ankle muscle or ligament rupture were excluded from the study). ${ }^{33-35}$ In addition, the limb dominance was identified by preferred limb applied to kick a ball. 36

\section{Data Collection}

Real-time musculoskeletal ultrasound scanning was performed with a GE Healthcare, Voluson E6 system. This system had an $18 \mathrm{MHz}$ linear array and $44 \mathrm{~mm}$ footprint probe. To determine the characteristics of ultrasonography, crosssectional area (CSA), thickness, width, fiber length, and pennation angle of PL muscle, the subject was made to lie in the supine position and the ankle was placed at a 90-degree dorsiflexion using an ankle-foot orthosis. Head of fibula and lateral malleolus was identified using a marker as landmark. Moreover, the linear probe was perpendicularly placed at 50 $\%$ of the distance between the afore-mentioned landmarks. ${ }^{33,37,38}$ Then, fiber length and pennation angle were measured by placing the probe parallel to the sagittal plane, with three repetitions, and finally, the average of these three measurements is considered. ${ }^{39}$ Later, the muscle dimensions were immediately calculated by on-screen-callipers. In addition, the maximum distance between the boundaries was considered during the measurement of thickness, width, and CSA. 40

\section{Image Analysis}

The muscle thickness or anterior posterior dimension $(\mathrm{cm})$ was measured at the centre of each image, and the linear perpendicular distance between aponeurosis, muscle width or lateral dimension $(\mathrm{cm})$ was the greatest from border to border, and CSA $\left(\mathrm{cm}^{2}\right)$ was measured by tracing the inside 
margin of the scan by ultrasound specialist.16,40,41 The fiber length $(\mathrm{cm})$ of the muscle was calculated by measuring the line plotted along the muscle fibers, from the beginning of one aponeurosis to the end of the other aponeurosis, and pennation angle (degree) was also measured as the angle between the muscle fiber length and the deep aponeurosis of its insertion. ${ }^{39,41}$ (Figure 1: a, b, and c).
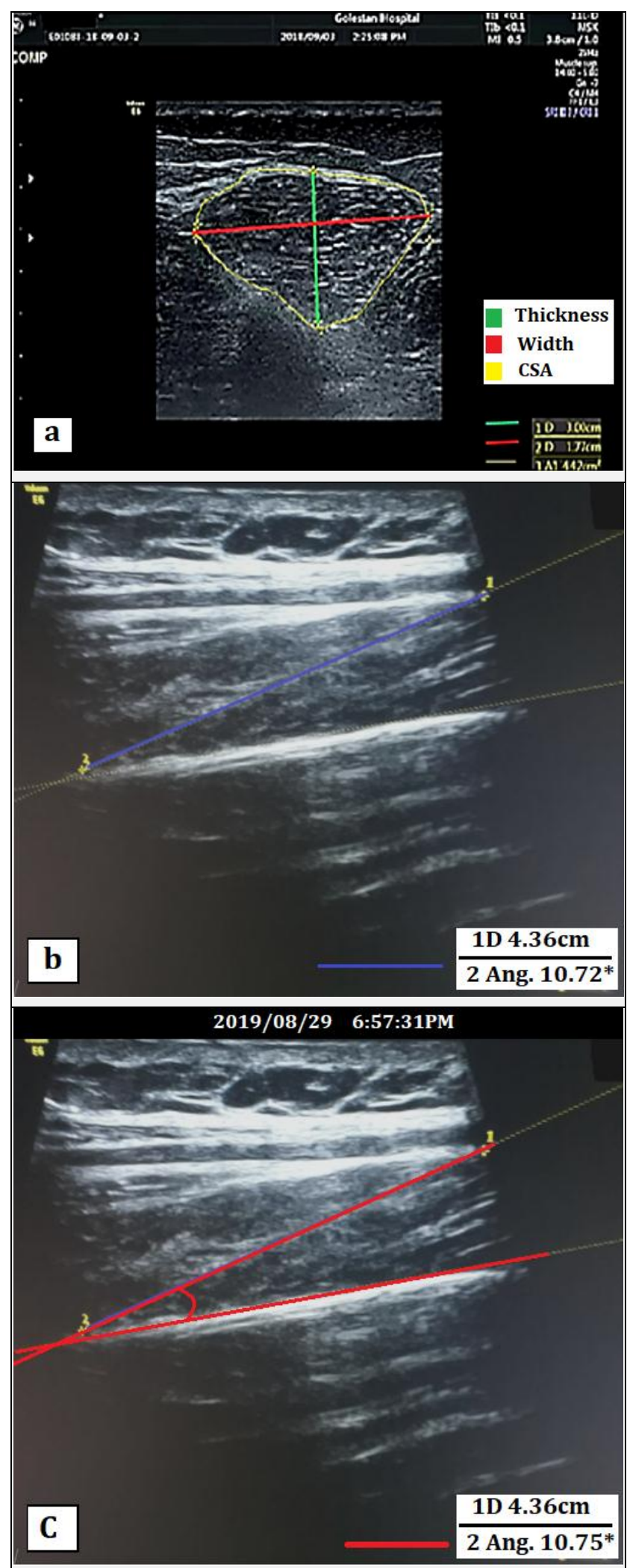

Figure 1. a) Thickness, Width and Cross-Sectional Area (CSA), b) Fiber Length, and c) Pennation Angle

\section{Statistical Analysis}

Statistical analyses were carried out using International Business Machines Statistical Package for the Social Sciences (IBM SPSS) statistical software (Version 22.0, IBM Corp, Armonk, New York). The statistical tests were also carried out regarding $95 \%$ confidence interval and $\mathrm{P}$ value $<0.05$ was considered statistically significant. In addition, the qualitative outcomes were presented as frequencies and percentages. Shapiro-Wilk test revealed the normal distribution of demographic variables ( $p$ value $>0.05$ ). Since repeated application of Wilcoxon signed-rank test for multiple variables leads to an increase in type I error, in this study, principal component analysis (PCA) was used to avoid inflated family wise type I error by performing the same tests on multiple correlated variables. PCA is a dimensionality reduction technique of the data set including a number of (possibly) correlated variables into a (smaller) number of uncorrelated variables without losing much information. The scores of principal components (with an eigenvalue $>1$ ) were included in generalised estimating equation (GEE) approach. GEE was used to account for the intra-person variability of analyzing both feet per subject. In addition, the $\chi 2$ test was used to compare the variables between the males and females.

\section{RESULTS}

Twenty-five subjects (14 males and 11 females) with unilateral CAI within the age range of $20-40$ years participated in this study. Out of these participants, 17 were right foot dominant and 8 were left foot dominant, among which 12 had right ankle sprain and 13 had left ankle sprain; in other words, in $64 \%$ of subjects, the dominant foot was injured.

\begin{tabular}{|ccc|}
\hline Variable & \multicolumn{3}{c|}{ Component } \\
CSA & $\mathbf{1}$ & $\mathbf{2}$ \\
Thickness & 0.938 & -0.025 \\
Width & 0.839 & -0.130 \\
Fiber length & 0.675 & 0.276 \\
Pennation angle & 0.474 & 0.623 \\
Eigenvalue & 0.478 & -0.730 \\
Percent of variance & 2.492 & 1.014 \\
Cumulative variance (\%) & 49.846 & 49.846 \\
\hline Table 1. Rotated Component Loadings of the One Principal Component \\
Including Eigen Values Greater Than One, Their Percentage of \\
Variance, and Cumulates Percentage of Variance in the PCA of PL \\
\hline CSA: Cross-Sectional Area \\
\hline
\end{tabular}

\begin{tabular}{|cccccc|}
\hline & & \multicolumn{2}{c}{$\begin{array}{c}\text { Morphological } \\
\text { Component }\end{array}$} & \multicolumn{2}{c|}{$\begin{array}{c}\text { Muscle Performance } \\
\text { Component }\end{array}$} \\
& B (95\% CI) & $\begin{array}{c}\text { P- } \\
\text { Value }\end{array}$ & B (95 \% CI) & $\begin{array}{c}\text { P- } \\
\text { Value }\end{array}$ \\
Intercept & -0.126 & 0.656 & 0.135 & 0.575 \\
$(-0.680 ; 0.428)$ & & $-0.338 ; 0.609)$ & \\
\hline $\begin{array}{c}\text { Intra-subject } \\
\text { (side) }\end{array}$ & Injured side & -0.345 & $0.025^{*}$ & 0.198 & 0.234 \\
$(-0.646 ;-0.044)$ & $-0.128 ; 0.525)$ & - \\
\hline $\begin{array}{c}\text { Injured side_ } \\
\text { same_ }\end{array}$ & Yes & 0.508 & - & - & - \\
Dominant limb & No & $(-0.102 ; 1.117)$ & 0.102 & -0.399 & 0.187 \\
\hline $\begin{array}{c}\text { Table 2. Estimated Effects of the Side and Dominant Limb Variables on } \\
\text { the Morphological and Muscle Performance Components of PL }\end{array}$ \\
\hline
\end{tabular}


Two principal components were obtained with eigenvalues $>1$ for PL muscle, to explain $70.13 \%$ of the total variance in the dataset. The first PCA accounted for $49.84 \%$ of the total variance. This can be interpreted as "morphological component." The second PCA can be used to characterize "muscle performance component" (Table 1), which contains fiber length and pennation angle. PL muscle GEE analysis displayed significant effect of side variable for morphological component. It is also showed no significant effects of the side and dominant limb variables for muscle performance component (Table 2).

\section{DISCUSSION}

The results of the present study show that the morphological component of PL muscle, which includes CSA, thickness, and width, are significantly reduced on the injured side compared to the intact side; but the performance component of muscle, which includes muscle fiber length and pennation angle, is not significantly different between the two sides.

Since 2016, there was no study investigating the structures of ankle muscles in intact and injured sides; however, two studies have investigated the differences in ultrasound characteristics of ankle muscles between healthy individuals and those with chronic ankle instability.16,33 Lobo et al., reported statistically significant differences in CSA of peroneus muscles between healthy and CAI groups. They observed that CSA was affected by groups. ${ }^{33}$ In the present study, there was a significant difference in morphological component of PL between the intact and injured sides in CAI; this finding is consistent with the study by Lobo et al., reporting the difference in CSA of PL muscle between subjects with and without CAI.

One of the important factors for muscle performance is muscle fiber length ${ }^{41}$ and optimum fiber length which is the main cause of differences in muscle force-length properties. $^{39,42}$ Muscles with longer fiber lengths have more sarcomeres in series leading to a greater muscle excursion. ${ }^{41}$ The velocity of contraction is calculated from the ratio of the radial maximum displacement and the sum of the contraction time and delay time. ${ }^{43}$ Therefore, considering no significant difference of muscle fiber length between the intact and injured sides in present study, muscle excursion property is approximately the same for both sides, and despite the delay time in $\mathrm{PL},{ }^{6}$ possibly the contraction velocity does not change significantly. There is no statistically significant difference in the pennation angle between the intact and injured sides in these subjects. These results could be justified by the fact that human body is always trying to save energy via moving with minimum energy consumption; therefore, to do this, body maintains pennation angle near optimal value to use ankle strategy (which is cost benefit) instead of hip strategy to maintain balance. ${ }^{44}$ In addition, there was not statistically significant difference in morphological and muscle performance components of PL muscle between injured and intact side in terms of the dominant limb. Since no differences in muscle performance component were found, using motor control strategies during inversion ankle sprain may be a more likely clarification for the differences between the injured and intact sides of ankles in subjects with unilateral CAI.
The results of this study also showed that, ankle sprain occurred in the dominant limb more frequently. Moreover, 64 $\%$ of subjects had ankle sprain in the dominant limb. This finding is consistent with the findings of a study conducted by Willmes et al. ${ }^{45}$ and it emphasizes the results of Ekstrand and Gillquist, ${ }^{46}$ who stated that $92 \%$ of the ankle injuries affected the dominant leg in football players. The dominant leg may be at the increased risk of injury because it is preferably used for kicking, pushing off, jumping or landing. However, there was no significant relationship between dominant leg and ankle sprain in other studies. 47,48 This contradiction in findings may be due to the different study designs and participants. The target population in previous studies was athletes, but in this study, athletes were not included, and non-athlete individuals were examined; also, the study design of other studies was prospective, while this study used a cross-sectional design. Other findings showed no statistically significant difference in the ultrasonographic characteristics between healthy and injured limbs, except for morphological component of PL. This study revealed no significant difference in ultrasonographic characteristics between genders and this is consistent with the results of the study by Verma. ${ }^{49}$ This is probably one of the reasons for the similar prevalence of ankle sprain between the males and females. ${ }^{50}$ The gender differences have not been considered in other studies. $16,33,51$

\section{CONCLUSIONS}

Musculoskeletal ultrasound was used to evaluate the CSA, thickness, width, fiber length, and pennation angle of peroneus longus muscle in people with chronic ankle instability. Among the aforementioned variables, difference in CSA, thickness and width as morphological components of PL muscle has been statistically significant between intact and injured sides. Results of this evaluation showed changes in the morphology of the injured side of the peri-ankle muscle compared to the intact side.

Data sharing statement provided by the authors is available with the full text of this article at jemds.com.

Financial or other competing interests: The financial support was provided by Ahvaz Jundishapur University of Medical Sciences (Ph.D. Thesis grant no.: PHT-9725).

Disclosure forms provided by the authors are available with the full text of this article at jemds.com.

\section{REFERENCES}

[1] Webster KA, Gribble WK. A comparison of electromyography of gluteus medius and maximus in subjects with and without chronic ankle instability during two functional exercises. Phys Ther Sport 2013;14(1):1722.

[2] Kirby AB, Beall DP, Murphy MP, et al. Magnetic resonance imaging findings of chronic lateral ankle instability. Curr Probl Diagn Radiol 2005;34(5):196-203.

[3] Ju SB, Park GD. Effects of the application of ankle functional rehabilitation exercise on the ankle joint functional movement screen and isokinetic muscular 
function in patients with chronic ankle sprain. J Phys Ther Sci 2017;29(2):278-81.

[4] McCriskin BJ, Cameron KL, Orr JD, et al. Management and prevention of acute and chronic lateral ankle instability in athletic patient populations. World J Orthop 2015;6(2):161-71.

[5] Pourkazemi F, Hiller CE, Raymond J, et al. Predictors of chronic ankle instability after an index lateral ankle sprain: a systematic review. J Sci Med Sport 2014;17(6):568-73.

[6] Hopkins JT, Coglianese M, Glasgow P, et al. Alterations in evertor/invertor muscle activation and center of pressure trajectory in participants with functional ankle instability. J Electromyo Kinesiol 2012;22(2):280-5.

[7] Panagiotakis E, Mok KM, Fong DTP, et al. Biomechanical analysis of ankle ligamentous sprain injury cases from televised basketball games: understanding when, how and why ligament failure occurs. J Sci Med Sport 2017;20(12):1057-61.

[8] Brown C, Padua D, Marshall SW, et al. Individuals with mechanical ankle instability exhibit different motion patterns than those with functional ankle instability and ankle sprain copers. Clin Biomech (Bristol, Avon) 2008;23(6):822-31.

[9] Brown CN, Mynark R. Balance deficits in recreational athletes with chronic ankle instability. J Athl Train 2007;42(3):367-73.

[10] Clark VM, Burden AM. A 4-week wobble board exercise programme improved muscle onset latency and perceived stability in individuals with a functionally unstable ankle. Phys Ther Sport 2005;6(4):181-7.

[11] Leavey VJ. The comparative effects of a six-week balance training program, gluteus medius strength training program, and combined balance training/gluteus medius strength training program on dynamic postural control. Morgantown: West Virginia University 2006.

[12] Vaes P, Duquet W, Van Gheluwe B. Peroneal reaction times and eversion motor response in healthy and unstable ankles. J Athl Train 2002;37(4):475-80.

[13] Huurnink A, Fransz DP, Kingma I, et al. Postural stability and ankle sprain history in athletes compared to uninjured controls. Clin Biomech 2014;29(2):183-8.

[14] Lin CY, Kang JH, Wang CL, et al. Relationship between viscosity of the ankle joint complex and functional ankle instability for inversion ankle sprain patients. J Sci Med Sport 2015;18(2):128-32.

[15] Papadopoulos E, Nicolopoulos C, Baldoukas A, et al. The effect of different ankle brace-skin interface application pressures on the electromyographic peroneus longus reaction time. The Foot 2005;15(4):175-9.

[16] Abdeen R, Comfort P, Starbuck C, et al. Ultrasound characteristics of foot and ankle structures in healthy, coper and chronically unstable ankles. J Ultrasound Med 2019;38(4):917-26.

[17] Akhbari B, Takamjani IE, Salavati M, et al. A 4-week biodex stability exercise program improved ankle musculature onset, peak latency and balance measures in functionally unstable ankles. Phys Ther Sport 2007;8(3):117-29.

[18] Gribble PA, Robinson RH. An examination of ankle, knee and hip torque production in individuals with chronic ankle instability. J Strength Cond Res 2009;23(2):395400.
[19] Linford CW, Hopkins JT, Schulthies SS, et al. Effects of neuromuscular training on the reaction time and electromechanical delay of the peroneus longus muscle. Arch Phys Med Rehabil 2006;87(3):395-401.

[20] Postle K, Pak D, Smith T. Effectiveness of proprioceptive exercises for ankle ligament injury in adults: a systematic literature and meta-analysis. Man Ther 2012;17(4):28591.

[21] Delahunt E, Coughlan GF, Caulfield B, et al. Inclusion criteria when investigating insufficiencies in chronic ankle instability. Med Sci Sports Exerc 2010;42(11):210621.

[22] Hass CJ, Bishop MD, Doidge D, et al. Chronic ankle instability alters central organization of movement. Am J Sports Med 2010;38(4):829-34.

[23] Wikstrom EA, Fournier KA, McKeon PO. Postural control differs between those with and without chronic ankle instability. Gait Posture 2010;32(1):82-6.

[24] Wikstrom EA, Bishop MD, Inamdar AD, et al. Gait termination control strategies are altered in chronic ankle instability subjects. Med Sci Sports Exerc 2010;42(1):197-205.

[25] Cheung K, Hume P, Walt S, eds. Biomechanical adaptations following a lateral ankle sprain injury: an explanation for chronic ankle instability? ISBSConference Proceedings Archive 2002.

[26] Arnold BL, Linens SW, de la Motte SJ, et al. Concentric evertor strength differences and functional ankle instability: a meta-analysis. J Athl Train 2009;44(6):65362.

[27] Hupperets MD, Verhagen EA, van Mechelen W. Effect of sensorimotor training on morphological, neurophysiological and functional characteristics of the ankle: a critical review. Sports Med 2009;39(7):591-605.

[28] Hadadi M, Takamjani IE, Mosavi ME, et al. Cross-cultural adaptation, reliability and validity of the persian version of the cumberland ankle instability tool. Disabil Rehabil 2017;39(16):1644-9.

[29] Bowker S, Terada M, Thomas AC, et al. Neural excitability and joint laxity in chronic ankle instability, coper and control groups. J Athl Train 2016;51(4):336-43.

[30] Kirby JL, Houston MN, Gabriner ML, et al. Relationships between mechanical joint stability and somatosensory function in individuals with chronic ankle instability. The Foot 2016;28:1-6.

[31] Linens SW, Ross SE, Arnold BL, et al. Postural-stability tests that identify individuals with chronic ankle instability. J Athl Train 2014;49(1):15-23.

[32] Terrier R, Degache F, Fourchet F, et al. Assessment of evertor weakness in patients with chronic ankle instability: Functional versus isokinetic testing. Clin Biomech (Bristol, Avon) 2017;41:54-9.

[33] Lobo CC, Morales CR, Sanz DR, et al. Ultrasonography comparison of peroneus muscle cross-sectional area in subjects with or without lateral ankle sprains. J Manipulative Physiol Ther 2016;39(9):635-44.

[34] Plante JE, Wikstrom EA. Differences in clinician-oriented outcomes among controls, copers and chronic ankle instability groups. Phys Ther Sport 2013;14(4):221-6.

[35] Wikstrom EA, Tillman MD, Chmielewski TL, et al. Discriminating between copers and people with chronic ankle instability. J Athl Train 2012;47(2):136-42. 
[36] van Melick N, Meddeler BM, Hoogeboom TJ, et al. How to determine leg dominance: the agreement between selfreported and observed performance in healthy adults. PLoS One 2017;12(12):e0189876.

[37] Angin S, Crofts G, Mickle KJ, et al. Ultrasound evaluation of foot muscles and plantar fascia in pes planus. Gait Posture 2014;40(1):48-52.

[38] Crofts G, Angin S, Mickle KJ, et al. Reliability of ultrasound for measurement of selected foot structures. Gait Posture 2014;39(1):35-9.

[39] Maganaris CN. Force-length characteristics of in vivo human skeletal muscle. Acta Physiol Scand 2001;172(4):279-85.

[40] Javanshir K, Mohseni-Bandpei MA, Rezasoltani A, et al. Ultrasonography of longus colli muscle: a reliability study on healthy subjects and patients with chronic neck pain. J Bodyw Mov Thera 2011;15(1):50-6.

[41] Chow R, Medri M, Martin D, et al. Sonographic studies of human soleus and gastrocnemius muscle architecture: gender variability. Eur J Appl Physiol 2000;82(3):236-44.

[42] Wickiewicz TL, Roy RR, Powell PL, et al. Muscle architecture of the human lower limb. Clin Orthop Relat Res 1983;(179):275-83.

[43] Loturco I, Pereira LA, Kobal R, et al. Muscle contraction velocity: a suitable approach to analyze the functional adaptations in elite soccer players. J Sports Sci Med 2016;15(3):483-91.

[44] Kazemi K, Arab AM, Abdollahi I, et al. Electromiography comparison of distal and proximal lower limb muscle activity patterns during external perturbation in subjects with and without functional ankle instability. Hum Mov Sci 2017;55:211-20.

[45] Willems TM, Witvrouw E, Delbaere K, et al. Intrinsic risk factors for inversion ankle sprains in females--a prospective study. Scand J Med Sci Sports 2005;15(5):336-45.

[46] Ekstrand J, Wiktorsson M, Oberg B, et al. Lower extremity goniometric measurements: a study to determine their reliability. Arch Phys Med Rehabil 1982;63(4):171-5.

[47] Beynnon BD, Renström PA, Alosa DM, et al. Ankle ligament injury risk factors: a prospective study of college athletes. J Orthop Res 2001;19(2):213-20.

[48] Surve I, Schwellnus MP, Noakes T, et al. A fivefold reduction in the incidence of recurrent ankle sprains in soccer players using the sport-stirrup orthosis. Am J Sports Med 1994;22(5):601-6.

[49] Verma P. Exploration of tibialis anterior in North Indian cadavers in relations to frequency, morphology, morphometry and its clinical importance. Int J Anat Res 2016;4(2):2376-80.

[50] Hertel J. Functional anatomy, pathomechanics and pathophysiology of lateral ankle instability. J Athl Train 2002;37(4):364-75.

[51] Simoneau-Buessinger E, Leteneur S, Bisman A, et al. Ultrasonographic quantification of architectural response in tibialis anterior to neuromuscular electrical stimulation. J Electromyogr Kinesiol 2017;36:90-5. 